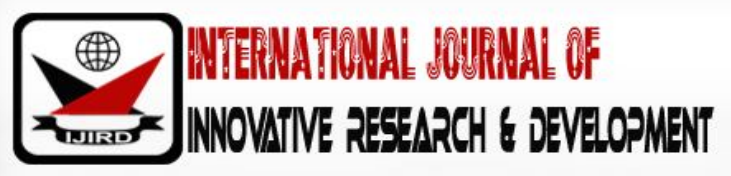

ISSN 2278 - 0211 (Online)

\section{Constraints, Challenges and Opportunities of Horticultural Crops Marketing in Ambo Town, Ethiopia}

\author{
Mosisa Chewaka Aga \\ Lecturer, Department of Horticulture, College of Agriculture and Veterinary Sciences, Ambo University, Ethiopia
}

\begin{abstract}
:
The study was conducted to investigate the constraints, challenges and opportunities of horticultural crops marketing in Ambo town. A total of 96 retailers were randomly selected for an interview. Both qualitative and quantitative analysis was made descriptively. Results of the study showed that both women and men participated in fruits and vegetables retailing business, of these and $41.7 \%$ of the respondents were between 20 to 30 years of age and 36.5\% were 30 to 40 years of age. The highest percentages (78.1\%) of the respondents had some education and were able to read and write. Almost all of the respondents were selling their commodities along the road side and in area where there is inconveniency for perishable products. Inappropriate marketing place, shade, storage, packaging and transportation practices were identified as principal causes for the fruits and vegetables post-harvest loss and short shelf-life in the study area. About 53.1\% post-harvest losses were found due to the lack of shade. Therefore, challenges are essentially required to support these retailers from different stakeholders in fruits and vegetables storage, transportation, infrastructures establishment, in sanitation of the market place through training and capacity development in the logistical supply chain to reduce the various losses.
\end{abstract}

Keywords: Constraints, opportunities, marketing, post-harvest, fruits, vegetable, Ambo, retailers

\section{Introduction}

Agriculture employs about 85\% of the labor force, contributes approximately over half of the GDP, accounts for about $90 \%$ of the foreign exchange earnings, and provides livelihood to over $90 \%$ of the Ethiopian population (Fantahun and Williamson,2001; Milaku,2005; Bezabih and Hadera, 2007). These all shows that agriculture is a predominant sector to the economy of Ethiopia.

Horticulture is one of the sub-sectors of agriculture from which many developing and developed countries have been benefiting a lot, not only for food self-sufficiency but also for sustainability of their economies (Ali, 2008; AgBit, 2015). Horticulture encompasses a number of crops and commodities ranging from fruits, Vegetables, root and tuber crops etc. Ethiopia has a suitable climatic and edaphic conditions for the production of various horticultural crops (Mulugeta, et al., 2017). However, the full economic potential of these horticultural crops has not yet been exploited (Haileab, 2017). Fruits and vegetables improve the composition and variation in the diet, and they also help in balancing nutrition and protecting vulnerable groups of the local population from their health disorders associated with low mineral and vitamin deficiencies (English and Badacock, 1998; Ali, 2008).

The sub-sector of fruits and vegetables in Ethiopia has a high potential for domestic, regional and international markets, but that substantial coordinated efforts and investments by both public and private sectors parties are essentially required to actually realize these potentials (Dessalegn, et al., 2016). Studies indicated that most of Ethiopia's fruits and vegetables are grown for local consumption. Having any rich resource and potential only would not be enough unless training, research and study is conducted to exploit properly those areas in very huge resources.

Although, the resources of human and material are devoted for different agronomic research activities and nearly half of horticultural crops are lost due to improper post-harvest handling (Alazar, 2007; Olayemi et al., 2010). Post-harvest losses and quality deterioration of horticultural crops are mostly caused by inappropriate post-harvest handling, microbial infection, insect and disease pests, perishability of the crop, environmental conditions like temperature, solar radiation, ventilation, etc. (Olayemi et al., 2010). It occurs through all or at least one of post-harvest activities such as harvesting, handling, storing, processing, packaging, transporting and marketing (Zenebe et al. (2015). Reduction of post-harvest losses and quality deterioration are essential in increasing food availability from the existing production. Minimizing this loss has an enormous significance for food security, economic growth and benefit of the society. Therefore, this survey was conducted to investigate 
the constraints, challenges and opportunities of horticultural crops in Ambo town of Ethiopia and to suggest best solution for the vital problems.

\section{Material and Methods}

\subsection{Description of the Study Area}

The study was conducted in Ambo town of central Ethiopia. Ambo town is located West Shewa zone, Oromia regional state at about $110 \mathrm{~km}$ from Finfine (Addis Ababa) on $8^{\circ} 59^{\prime} \mathrm{N}$ latitude and $37^{\circ} 51^{\prime} \mathrm{E}$ longitude. It is found on an average elevation of 2100 meters above sea level and characterized by hot and humid weather with an average temperature of $19^{\circ} \mathrm{C}$. It receives $1416 \mathrm{~mm}$ rainfall annually and has distinct dry and wet seasons. It is one of the high potential areas for crop production in Ethiopia.

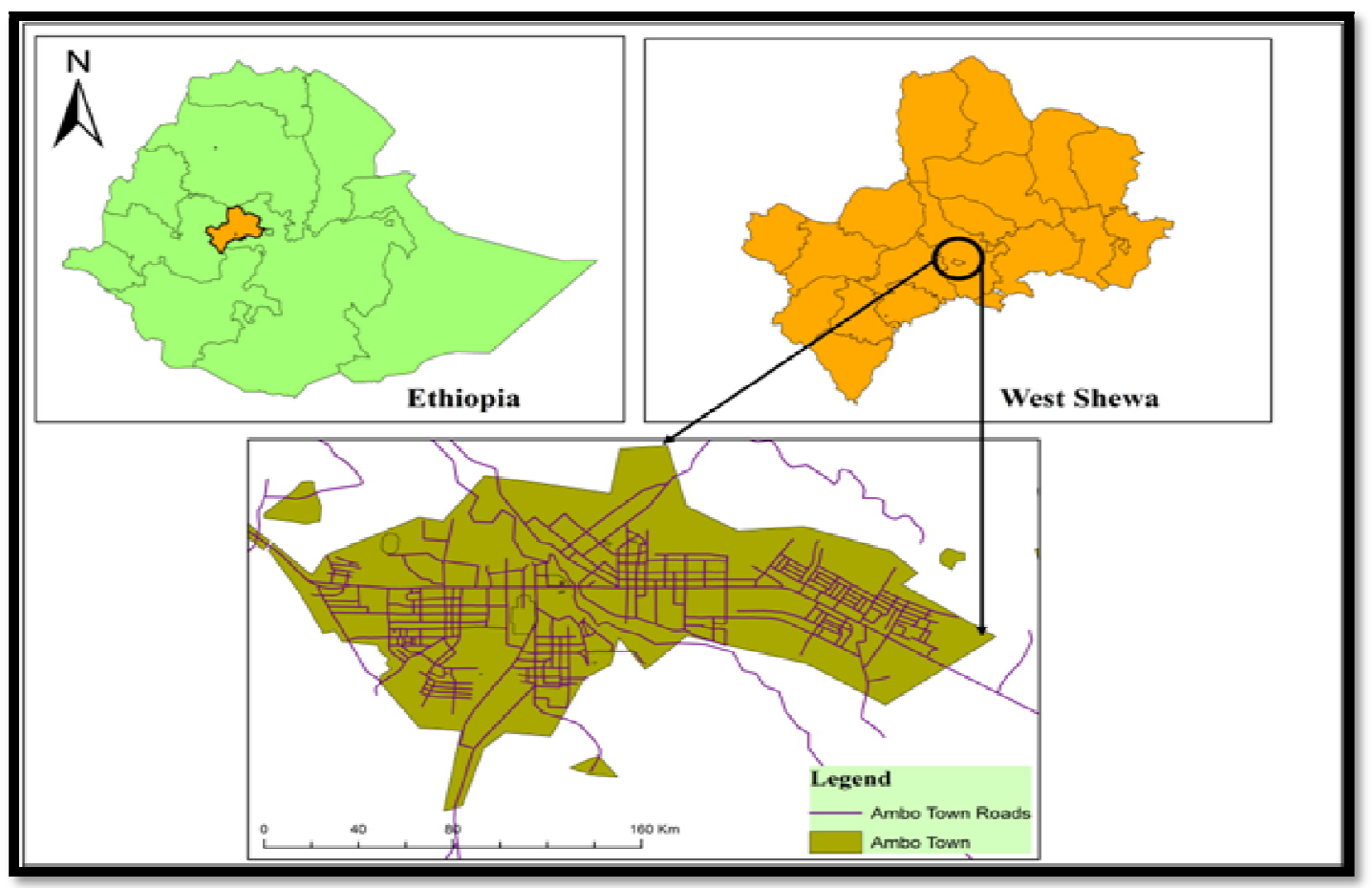

Figure 1: Geographical Location of Ambo Town

Source: Ambo University College of Agriculture and Veterinary Science GIS Team

\subsection{Sampling, Data Collection and Analysis}

Ninety six respondents were randomly selected from fruits and vegetables retailers in Ambo town. The survey was conducted from mid May to June 2017 using semi-structured questionnaire following individual interview method. Both qualitative and quantitative data including age, sex, education level and length of marketing experience of respondents, type of horticultural crops they are selling, type of packaging material, transportation method, storage facility, source of crops, percentage of loss, causes of losses, possible uses of over-ripen crops, and measures taken by respondents to reduce postharvest losses were collected and analyzed descriptively.

\section{Results and Discussion}

\subsection{Socio-Economic Characteristics of Respondents}

Results of the study show that women and men participate in fruits and vegetables retailing business in Ambo town (Table 1). However, the highest proportions are women followed by men which account $88.5 \%$ and $11.5 \%$, respectively. This finding agrees with the other African countries in that the women dominated the horticulture marketing business (Kughur et al., 2015; Mashau et al., 2012).

A total population of Ambo town is estimated to be 107,980 of which $29 \%$ were youth (CSA, 2014). Figure 2 showed that $41.7 \%$ of the respondents were between 20 to 30 years of age and $36.5 \%$ were 30 to 40 years of age, $9.4 \%$ were 10 to 20 years of age, $8.3 \%$ were 40 to 50 years of age, and $4.2 \%$ were greater than 50 years age. This implies that the majority's retailers are less than 40 years old. The current finding agreed with the report of Dessalegn et al. (2016), which indicated that the fruit retailing business in Bahir Dar city was dominated by youth. 
The highest percentages of (78.1\%) the respondents had some education and were able to read and write. These indicated these respondents were educated and have attended above the primary school. About $21.9 \%$ of the respondents had no formal education (Table 1).This is a great opportunity for horticulture marketing in the town to modernize the system if they are supported by proper training and guidance with the concerned body. However, the respondents were interviewed whether they had training on the nature fruits and vegetables, post-harvest handling and storage condition, hygiene and marketing information of these crops but all of them replied that they could not get any support so far in this regard.

\begin{tabular}{|c|c|c|c|}
\hline Variable Description & Categories & Frequency & Percent \\
\hline Gender of respondent & 1=Female & 85 & 88.5 \\
& 0=Male & 11 & 11.5 \\
\hline Literacy of household & 0=Illiterate & 21 & 21.9 \\
& 1=Read and write & 75 & 78.1 \\
\hline Marital Status of respondent & 1=Married & 77 & 80.2 \\
& 2=Unmarried & 9 & 9.4 \\
& 3=Divorced & 1 & 1.0 \\
& 4=Widowed & 9 & 9.4 \\
\hline Occupation & 1=Farmer & 10 & 10.4 \\
& 2=Merchant & 77 & 80.2 \\
& 3=Government worker & 0 & 0.0 \\
& 4=Daily worker & 5 & 5.2 \\
& 5=0ther & 4 & 4.2 \\
\hline Work experience & 1=<6month & 8 & 8.3 \\
& 2=1year & 15 & 15.6 \\
& 3=2-3years & 26 & 27.1 \\
& 4=>4 years & 47 & 49.0 \\
\hline
\end{tabular}

Table 1: Socio-Economic Characteristics of the Respondents ( $\mathrm{N}=96)$

Source: Survey Data (2017)

Results in Table 1 show that $80.2 \%$ of respondents married while the widowed and singles are $9.4 \%$, and about $1 \%$ are divorced. Like that of UN-HABITAT (2008) report where in the average family size of the respondents per family was five.

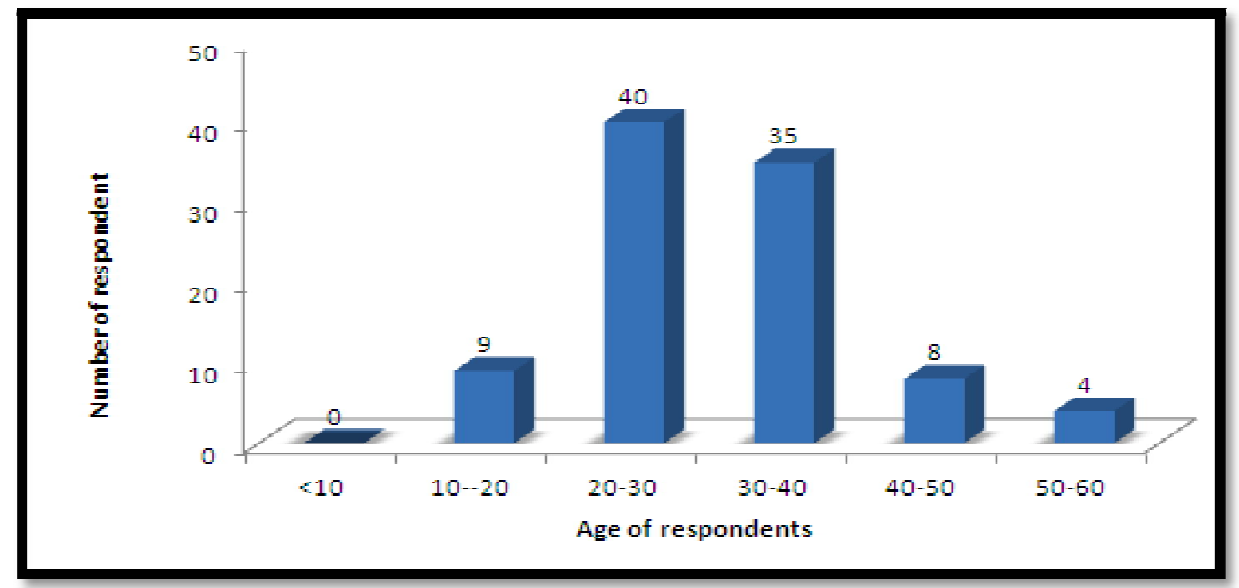

Figure 2: Age Category of the Respondent in Ambo Town: Survey Data (2017)

As indicated in Table 1 only 10.4\% the respondents were producers and sell fruits and vegetables in Ambo town. The majority ( $80.2 \%$ ) of the respondents were the retailer. The results in Table 1 also revealed that $49 \%$ of respondents have been in horticulture crops retailing business for more than four years, $27.1 \%$ of them for two to three years, $15.6 \%$ of them for more than a year and about $8.3 \%$ of them had less than six month experience in horticulture business. This implies that most of the retailers have less practical experience in retail business.

\subsection{Horticultural Marketing in Ambo Town}

Fruits and vegetables are produced in some particular locations around Ambo and supplied to the markets. Among the major markets identified for collection and distribution of Fruits and Vegetables 56.3\% were from Arada, 27.1\% from Gaba Bakala, and 16.7\% respondents were from 01 Kebel along the road side. The market actors namely producers, collectors or brokers, transporters, retailers, and consumers play different roles along the market chain (Figure 2). 


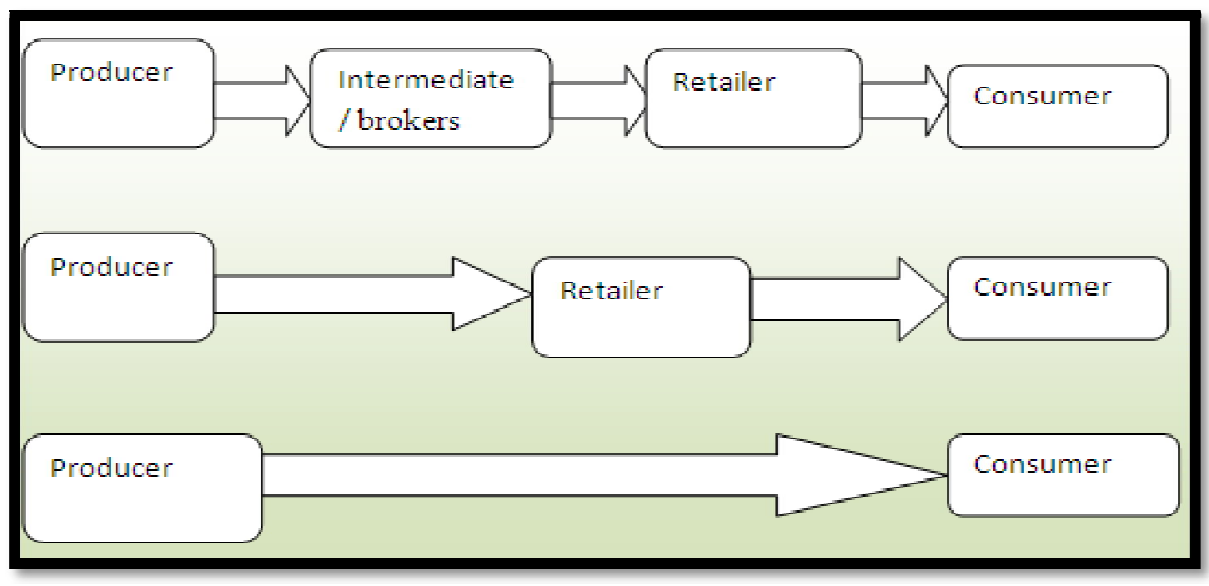

Figure 3: The Fruit and Vegetable Market Chain in Ambo Town: Survey Data (2017)

Fruits and vegetables, particularly Potatoes, Onions, Tomatoes, Cabbages, Carrots, Pepper, and Garlic are major vegetables crops existing in the horticulture market in Ambo. Among fruit crops, Banana (Musa spp.), Mango (Mangifera indica L.) and Lemon (Citrus limon) are the leading and existing in the market (Fig.3). Many other products such as Pineapple (Ananas comosus L.), Green Bean, Apple, Guava (Psidium guajava L.), etc. are also found at relatively smaller quantities in the market (Fig.3). However, the marketing of these products are seasonal. The Fruits and vegetables are often supplied from the nearby Kebele and Woredas like Awaro, Ginchi, Gossu, Gudar and Wadessa while relatively less perishable and highly demanded Fruit and Vegetables such as Banana, Avocado, Pineapple and onions, are also supplied from markets in Finifine (Addis Ababa), Oromia. Hence, these products (especially onion/ shallot) are transported from eastern Shewa to Finfine and then to Ambo.

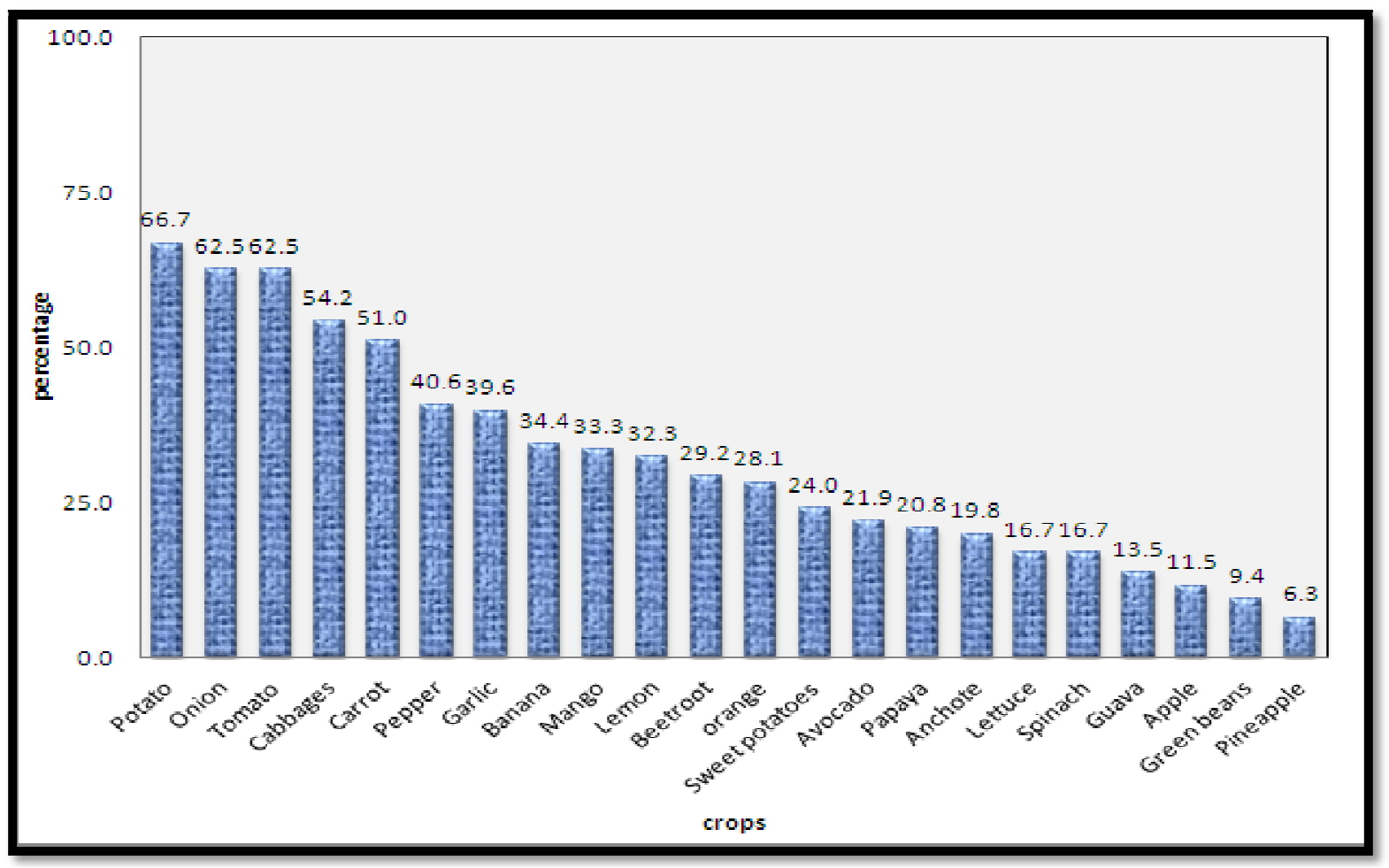

Figure 4: Major Horticultural Crops Sold by Retailers in Ambo Town: Survey Data (2017)

\subsection{Opportunity}

CSA, (2014) report indicated that unemployment rate was found to be $16 \%$ of which $6.63 \%$ for male and $9.37 \%$ for female. The survey result shows that $56.2 \%$ the respondent practice this horticultural market as their main occupation, while $42(43.8 \%)$ of them have other occupations such as temporary jobs, other trading, pension allowances and few of them combine farming. Research of the world development report 2008, indicates that horticulture revolution can benefit the poor by generating the employment and income opportunities in commercialization of horticulture (Ali, 2008). In addition AgBit, 
(2015) reported that the transformation of horticulture sub sector played great role in Zambia economy by creation of jobs and income generation through increased investment in focused value chain actors such as producers (farmers) processors, transporters, input and equipment suppliers, marketers and information system managers.

Beside an income generation these horticultural crops serve the respondents as food for their family. The respondents were asked the probable use over ripe fruits and vegetables they are selling and 66 (67.7\%) replied they use about the quarter of their products for consumption. This implies horticulture is benefiting the respondents and their families in eradicating deficiency. This is because the consumption of fruits and vegetables will lead to increase in availability of different vitamins and minerals that can have chances reducing malnutrition as result of deficiencies. Ali (2008), reported that the consumption of vegetables in Bangladesh reduced chances of night blindness in children due the availability of vitamin A. Similarly many studies suggested that the antioxidants and micronutrients found in fruits and vegetables have important health benefits like the higher birth weight of children, protecting different types of cancer, reduction in diarrhea, respiratory infection and stunted growth (English and Badacock, 1998; Ali, 2008).

\subsection{Challenges}

\subsubsection{Inappropriate Marketing Conditions}

The survey data showed that almost all of the respondents were selling their commodities along the road side and in area where there is inconvenient for perishable products (Fig.5). Due to lack of different know how about the post-harvest handling practice, absence of shade and storage, physical damage during transportation and other related factors leads to low price and deterioration of the product untimely.

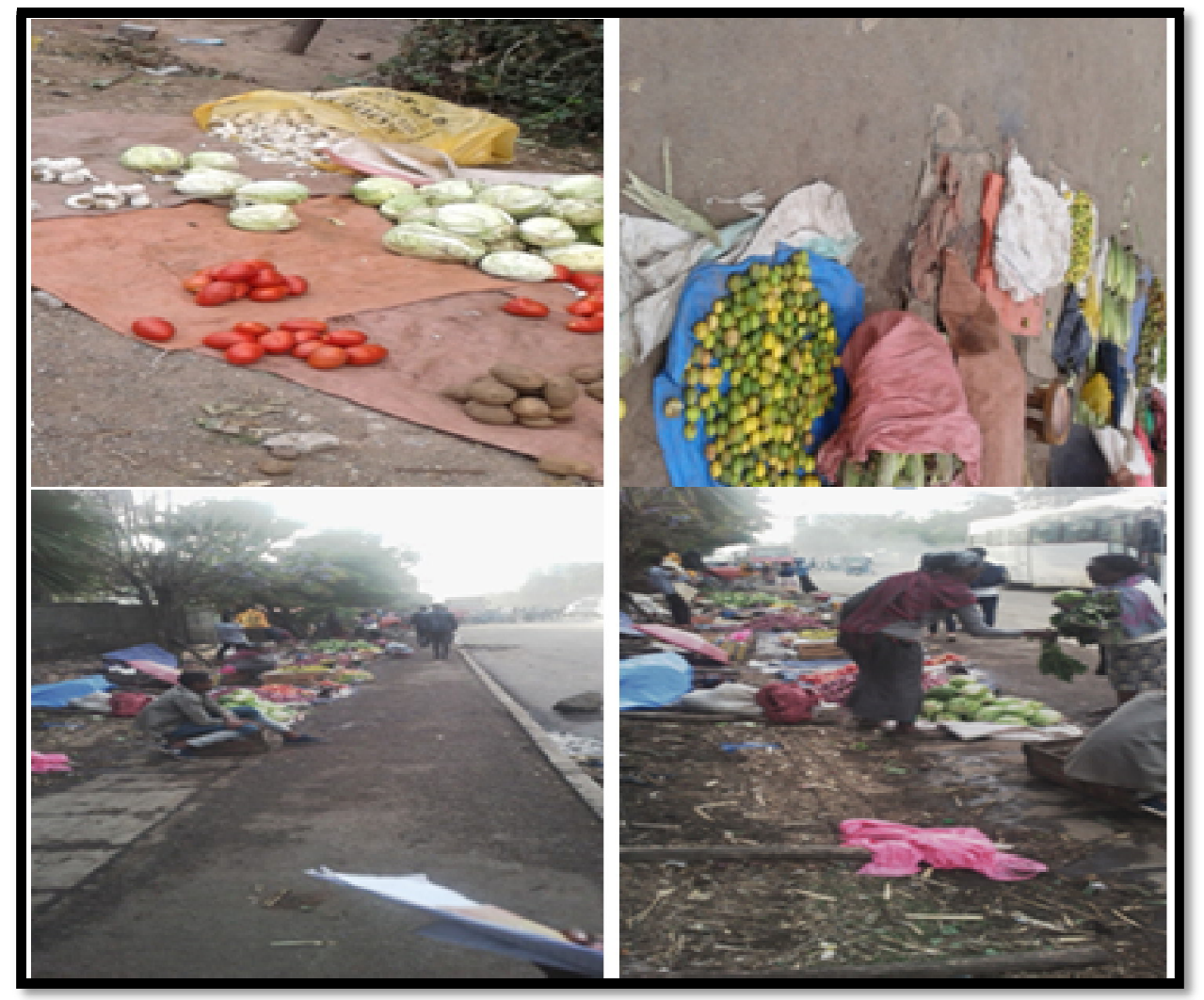

Figure 5: Market areas fruit and vegetables in Ambo town

Besides in sufficient product handling techniques there were a number of challenges in horticulture marketing in Ambo town. Lack of permanent and appropriate work place, lack of access to credit service, limited and seasonality of the product supply, lack of standards both in quantity and quality of the product, and unfair pricing some of the dominant problems reported by the respondents. Zenebe et al. (2015) identified that lack of appropriate facilities like Packaging, storage and transportation together with perishable nature of the produce results in marketing inefficiency. 


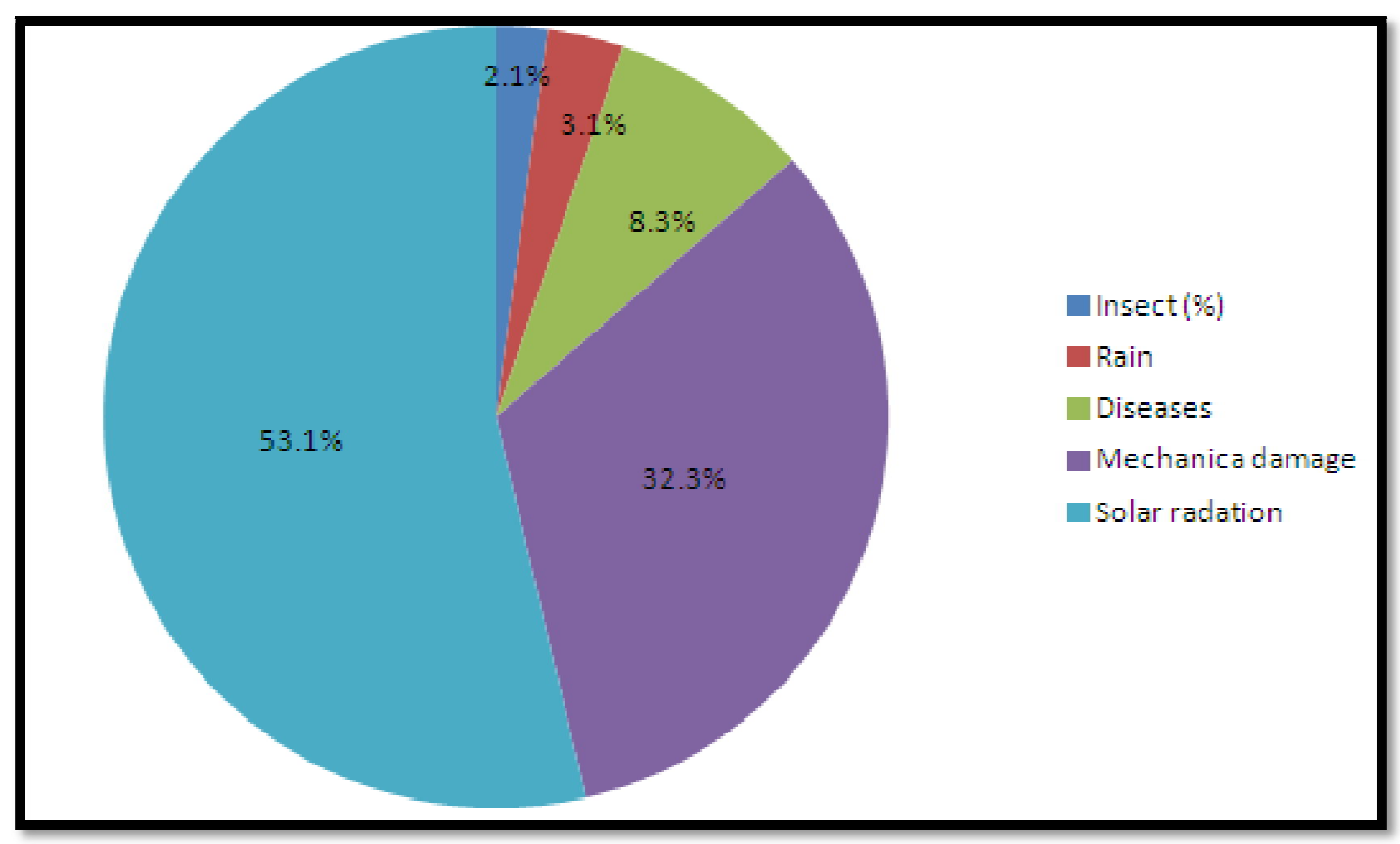

Figure 6: Causes of Losses of Horticultural Crops at Ambo Town as Mentioned by Respondents (Date Taken In June 2017)

Results revealed $53.1 \%$ of the respondents confirmed that post-harvest loss of their product is lost due to solar radiation (Fig 6). This was not surprising that since the marketing of the horticultural crops in open road side without any shade in the entire three places. When the handling at transportation and market place is poor, these products lose their moisture contents, and get shriveled or wilted. Research indicated that the most damaging factors for horticultural products are mechanical damage that create conducive environment for micro-organism, lack of well ventilated storage, high temperature during transportation and marketing facilities (Baloch, and Bibi, 2012). Kasso and Bekele (2016) reported that logistics along the value chain of horticultural marketing are very conventional. As a result, the sellers are forced to sell in traditional prices. The support given to maintain the nutritional quality and reduction of post-harvest loss of horticultural crops from the concerned bodies is nil. In addition, Dessalegn et al. (2016) stated that at higher temperature the shelf-life of horticultural crops were short because it enhances the ripening process and subsequently leads to deterioration. Therefore, effective, efficient strategies and urgent intervention to the existing problems is extremely required.

\section{Conclusion}

The fruit and vegetable sector has good perspectives and provides interesting opportunities for retailers in Ambo town. The result of this study clearly confirms that, fruits and vegetables marketing is largely handled by young and relatively educated individual households. The sector is however still in its infant stage. Facilitating conditions for doing business are not yet optimal. Inappropriate marketing place, storage, packaging and transportation practices are identified as principal causes for the fruits and vegetables post-harvest loss and short shelf-life in the study area. About $53.1 \%$ post-harvest loss is due to the lack of shade. Therefore, efforts required to support these retailers from different stakeholders on fruits and vegetable storage, transportation, infrastructures establishment, in sanitation of the market place through training and capacity development in the logistical supply chain to reduce loss. Perhaps, this can be addressed through simplified training targeting the level of their education. Organizing unity amongst retailers and producers so that they can work as partners; building both retailers and producers' business capacity, helping them to overcome their constraints and facilitating their use of market information, correcting the market through institutionalization of the marketing system, coordinating the functioning of market brokers, implementing a grades and standards system, and improving the system by improving the transparency in the price setting. The most important is the concerned government body should provide the appropriate market place for selling fruits and vegetables.

\section{Acknowledgments}

The author would like to thank and praise the Almighty God in giving strength and wellbeing to successfully complete the study. The author also acknowledges Ambo University for providing sufficient fund to do the research. In addition, my sincere appreciation also goes to the respondents who gave their time to respond to the questions. Finally, my deepest gratitude to 2017 Graduating class of Horticulture and Plant Science students for their help during the data collection by communicating the respondent with local language of Afan Oromo. 


\section{References}

i. Alazar, A., (2007). Horticultural Marketing in Ethiopia. M.Sc. Thesis. Haramaya University, Haramaya.

ii. Ali, M., (2008). Horticulture Revolution for the Poor: Nature, Challenges and Opportunities. Washington, DC: World Bank. (C) World Bank.

iii. AgBit (2015). Horticulture Sub-Sector study report 2015. Mapping Investment Opportunities in Horticulture SubSector: The Case of Vegetable Value Chains in Zambia

iv. Baloch, M., and Bibi, F., (2012). Effect of harvesting and Storage conditions on the post harvest quality and shelf life of mango (Mangifera indica L.) fruit. South African journal of botany 83:109-116.

v. Bezabih, E., Hadera, G., (2007). Constraints and problems of horticulture production and marketing in Eastern Ethiopia. Dry land Coordination Report, G46, Osolo, p. 91.

vi. CSA (2014). Urban Employment/ Unemployment Survey. FDRE, Central Statistic Authority. Addis Ababa, Ethiopia.

vii. Dessalegn, Y., Assefa, H., Derso, T., and Haileslassie, A., (2016). Assessment of fruit postharvest handling practices and losses in Bahir Dar, Ethiopia. Afri. J. Agr. Res. 11(52):5209-5214.

viii. English, R. and BadocockJ., (1998). A community nutrition project in Vietnam: effect on child morbidity. Food, Nutrition and Agriculture 22:20-27

ix. Fantahun, A., Williamson, S., (2001). Ethiopian farmers test alternatives to pesticides. Pestic. News 52:8-9.

x. Haileab, A., (2017). Characterization of the Production and Export Performance of the Flower Industry in Ethiopia. In: Mulugeta D., Weyessa G., Terefe B., Derebew B., and Amsalu N. (eds). 2017. Proceeding of the fifth Biennial Conference of Ethiopian Horticulture Science Society (EHSS), Volume 5:14-15 February 2015, Samara, Ethiopia.

xi. Kasso, M., Bekele, A.(2016). Post-harvest loss and quality deterioration of horticultural crops in Dire Dawa Region,Ethiopia. Journal of the Saudi Society of Agricultural Sciences. http:/ / dx.doi.org/ 10.1016/ j.jssas.2016.01.005

xii. Kughur, PG, Iornenge, GM, Ityonongu, BE. (2015). Effects of post-harvest losses on selected fruits and vegetables among small-scale farmers in Gboko local government area of Benue State, Nigeria. Int. J. Innov. Sci.Res. 19 (1):201208.

xiii. Milaku, J. (2005). Patterns and determinants of fruits and vegetables demand in developing countries: a multicountry comparison (Ethiopia). Fruit and Vegetables for Health. Report of a Joint FAO/WHO Workshop, 1-3 September 2004, Kobe.

xiv. Mashau, M.E, Moyane, J.N, Jideani, I.A (2012). Assessment of post-harvest losses of fruits at Tshakhuma fruit market in Limpopo province, South Africa. Afr. J. Agric. Res. 7(29):4145- 4150.

xv. Mulugeta D., Weyessa G., Terefe B., Derebew B., and Amsalu N., (eds). 2017. Proceeding of the Fifth Biennial Conference of Ethiopian Horticulture Science Society (EHSS), Volume V:14-15 February 2015, Samara, Ethiopia.

xvi. Olayemi, F., Adegbola, J., Bamishaiye, E., Daura, A.,(2010). Assessment of Post-harvest challenges of small scale farm holders of tomatoes, bell and hot pepper in some local government areas of Kano State, Nigeria. Bayero J. Pure Appl.Sci.3:39-42.

xvii. UN-HABITAT (2008). Ethiopia: Ambo Urban Profile. ISBN: 978-92-1-131980-4

xviii. Zenebe, W., Ali, M., Derbew, B., Zekarias, Sh., Adam, B., (2015). Assessment of Banana Post-harvest Handling Practices and Losses in Ethiopia. Journal of Biology, Agriculture and Healthcare. Vol.5, No. 17. 